\title{
Risk-based estimation of manufacturing order costs with artificial intelligence
}

\author{
Grzegorz Kłosowski \\ Lublin University of Technology, Faculty of \\ Management, Department of Enterprise Organization, \\ Lublin, Poland \\ Email: g.klosowski@pollub.pl
}

\begin{abstract}
The following paper discusses the development of a risk-based cost estimation model for completing non-standard manufacturing orders. The model in question is a hybrid of Monte Carlo Simulation (MCS), which constitutes the main module of the applied model. Vector of order risk probability, which is the input data for the MCS module, is highly difficult to assess and is burdened to a considerable degree with subjectivity, therefore it was resolved that it should be generated with the application of artificial intelligence. Depending on the accessibility of historical data, the model incorporates fuzzy logic or artificial neural networks methods. The presented model could provide support to managers responsible for cost estimation, and moreover, after slight modification also in setting deadlines for non-standard manufacturing orders.
\end{abstract}

\section{INTRODUCTION}

Analysis of trends in the development and operation of modern manufacturing enterprises indicates that competitiveness of an enterprise can by improved mainly through innovation in the fields of: manufactured products, technology, management and marketing [1]. Introducing new products into the offer [2], improving manufacturing and support processes [3] is becoming increasingly hard owing to rising costs and strong market competition, particularly from big enterprises. An outstanding advantage of small and medium-sized enterprises (SME) consists in their flexibility, which enables them to compete successfully for non-standard and low-batch orders [4]. Realisation of such orders usually requires accepting a project approach, which demands scheduling times, resources and costs with every order [5]. Correct cost and order delivery estimation is imperative, as the contract with the customer must specify such arrangements as order delivery date and cost.

Non-standard manufacturing orders realised by mediumsized enterprises include, for instance:

- special tool orders for big enterprises, used in largebatch production,

- matrices and punches,

- custom machines and appliances (e.g. paper tube and core making machines, CNC nesting machines, storage systems etc).

The literature describes a range of various attempts at classification of risk, which proves it to be complex a and multidimensional phenomenon [6]. Risk modelling is a developing and ongoing process [7], which causes that risk is frequently among the major factors behind miscalculation of non-standard order costs [8]. There is a crucial necessity for cost estimation method that would cover all estimation factors. There are many proposals that lack scientific justification for the produced results, i.e. lack technical description of how the results were achieved [9].

\author{
Arkadiusz Gola \\ Lublin University of Technology, Faculty of \\ Mechanical Engineering, Institute of Technological \\ Systems of Information, Poland \\ Email: a.gola@pollub.pl
}

In the case of non-standard orders, the risk of untimely delivery or exceeding the budget increases. Efficient cost estimation for diverse manufacturing orders becomes more complicated with the increasing number of factors that remain beyond the control of the manufacturer. These factors include uncertainty of any cooperative tasks, changing currency exchange rates, strict design or material requirements or industrial accidents [10]. Missing deadlines often results in enforcing contractual fines, losing customers and tarnishing the company's reputation, the last one being one of the key assets of any company and a critical success factor

Given the circumstances, it becomes a matter of high importance to develop an efficient method for risk minimisation concerning time and cost estimation of nonstandard manufacturing orders [11].

\section{CONCEPT}

There are three major indicators for the effectiveness of risk-based time-cost estimation of manufacturing orders: accuracy, time effectiveness and applicability. Clearly, solving these problems would not be possible without the application of IT solutions, which can meet the aforementioned criteria. Therefore, enterprises apply expert systems oriented towards aiding the decision-making process in the field of order cost estimation. The market offers numerous software solutions integrating business and production processes, nevertheless, the analysed case is more elaborate and therefore calls for a more versatile tool. Here, the input quality data must be correlated with results of quantitative character, i.e. time and cost.

The body of literature points at several methods for estimation of project risk. The most commonly used is the Monte Carlo Simulation (MCS), along with such methods as Artificial Neural Networks (ANN), Fuzzy Logic (FL), and Support Vector Machines (SVM) [12].

What contributes to the popularity of MCS is its uncomplicated applicability. MCS is a quantitative method that consists in building probability distribution for any risk involved. The consequences of unforeseen incidents could lead to unplanned change of costs or order delivery date, which in small-batch/non-standard orders as described here, is understood as a project.

A marked disadvantage of the method is the need for deterministic estimation of particular project risks probability. It is usually carried out by a single expert or a group of experts representing vast knowledge in a given discipline or branch. Eventually, this is still a subjective evaluation of probability, which is exactly one of the key drawbacks of MCS. 
One of the most popular ANN methods is multilayer perceptron (MLP). In this variation of ANN it is required that a sufficiently large quantity of suitable historical data is available, which could be then used as input in train, test and validation sets. Another problem is to find cause-and-effect relationship between suitably selected input data sets and order delivery date.

SVM resembles to a certain extent ANN/MLP, inasmuch as it requires a set of historical data to conduct the training process. One advantage over ANN is that SVM training always finds a global minimum and that it mitigates the risk of overtraining, however, the estimation with this method is quite time inefficient.

Fuzzy logic (FL) can be put to use in time-cost risk assessment, particularly when no historical data is available [13]-[14]. The method employs several heuristics, which are developed with e.g. Delphi method [15] or Brainstorming. Heuristics are recorded as reasoning rules, which in the next stage provide the core for the fuzzy inference system [16]. Apart from the reasoning rules, this method requires selection of suitable inputs, membership functions and defuzzification.

The short descriptions of each method indicate clearly that each model is burdened with certain limitations of different magnitude, which makes it difficult to apply in estimation of costs and time of individual orders, which can be treated as separate projects.

In order to eliminate the negative impact of subjective estimation, present in the classical MCS, AI can be applied in probability estimation of particular project risks.

Enterprises that do not possess historical data that could be used for training neural network or SVM controller could employ the FL method.

The proposed hypothesis for the application of a hybrid system, incorporating AI for percentage estimation of project risks in Monte Carlo method, will increase the accuracy of the MCS.

The second hypothesis states that determining the probability of project risks with the application of artificial intelligence is more reliable than the deterministic method, based on the subjective opinion of experts.

\section{PROPOSED METHODOLOGY}

Table 1 shows an exemplary project risk calculation of non-standard manufacturing orders carried out with Monte
Carlo simulation. Column 1 contains Risk Breakdown Structure. Column 2 specifies identified risks. Column 3 shows subjectively estimated particular risk probability. Column 4 contains costs of risk that would have to be covered if the risk occurred. An analogical approach could be accepted in determining the risk of untimely delivery dates, by substituting cost with time. In such a case, the set of risks in column 2 would be different as well.

Column 5 shows an expected number of risks, which is a product of columns 4 and 5. The sum of column 5 amounts to $71.50 \mathrm{EUR}$, which would not cover the potential expenses should the risks R-1, R-2 or R- 6 take place. Columns 6 and 7 enable simulation of numerous risk-related variants. Column 6 shows a function randomly generating absolute numbers from the range $<0,1)$. Column 7 contains logical conditional formulas:

$$
\text { IF }(\text { col.3) }>=(\text { col.6) THEN (col.4) }
$$

The sum of column 7 contains the cost of risk in the simulated case. After 1000 simulations with the random number generator and formula (1) cumulative distribution function was obtained, whose part is shown in Fig. 1.

The $\mathrm{x}$-axis shows costs of risk for particular scenarios, the $y$-axis the number of scenarios population, counted as a percentage share of probable situations. The best-case scenario estimates that the project risk amounts to 50 EUR.

Planning the budget for the realisation of order must account for two opposite goals: cost and risk minimisation. Increasing the budget by 600 EUR for the minimisation of project risk would result in a practically $100 \%$ guarantee that the project expenses will not exceed the budget. Nevertheless, excessive costs might not be covered by the customer, which is why, compromise solutions must be sought. It can be assumed that the acceptable compromise is setting the cost risk level at approx. $80 \%$. Broken lines in Fig. 1 show the $84 \%$ level of probability, corresponding to 160 EUR of additional risk-related cost it can be observed that the majority of all analyzed scenarios are on the left of that amount.

To remove the element of subjectivity, artificial intelligence can be applied in probability selection of particular risks (Table 1, column 3)

The algorithm for the development of a hybrid system for estimation of project risks is shown in Fig. 2.

TABLE I.

QUANTITATIVE ANALYSIS OF PROJECT RISKS MONTE CARLO SIMULATION

\begin{tabular}{|c|c|c|c|c|c|c|}
\hline RBS & Risk description & Probability & Cost & Level & RAND() & Simulation \\
\hline 1 & 2 & 3 & 4 & 5 & 6 & 7 \\
\hline $\mathrm{R}-1$ & Subcontractors errors & $10 \%$ & $€ 150.00$ & $€ 15.00$ & $60.6 \%$ & \\
\hline $\mathrm{R}-2$ & Currency exchange rate changes & $5 \%$ & $€ 300.00$ & $€ 15.00$ & $1.0 \%$ & $€ \mathbf{3 0 0 . 0 0}$ \\
\hline $\mathrm{R}-3$ & Lack of resources & $10 \%$ & $€ 50.00$ & $€ 5.00$ & $85.7 \%$ & \\
\hline $\mathrm{R}-4$ & Order requirements problems & $50 \%$ & $€ 10.00$ & $€ 5.00$ & $22.3 \%$ & $€ \mathbf{1 0 . 0 0}$ \\
\hline $\mathrm{R}-5$ & Supplier's delay [14] & $20 \%$ & $€ 20.00$ & $€ 4.00$ & $81.3 \%$ & \\
\hline $\mathrm{R}-6$ & Computer network failure & $30 \%$ & $€ 100.00$ & $€ 30.00$ & $96.0 \%$ & \\
\hline $\mathrm{O}-1$ & Supplier discount & $5 \%$ & $-€ 50.00$ & $-€ 2.50$ & $3.1 \%$ & $-€ 50.00$ \\
\hline \multicolumn{4}{|c|}{ Sum: } & $€ 71.50$ & & $€ 260.00$ \\
\hline
\end{tabular}




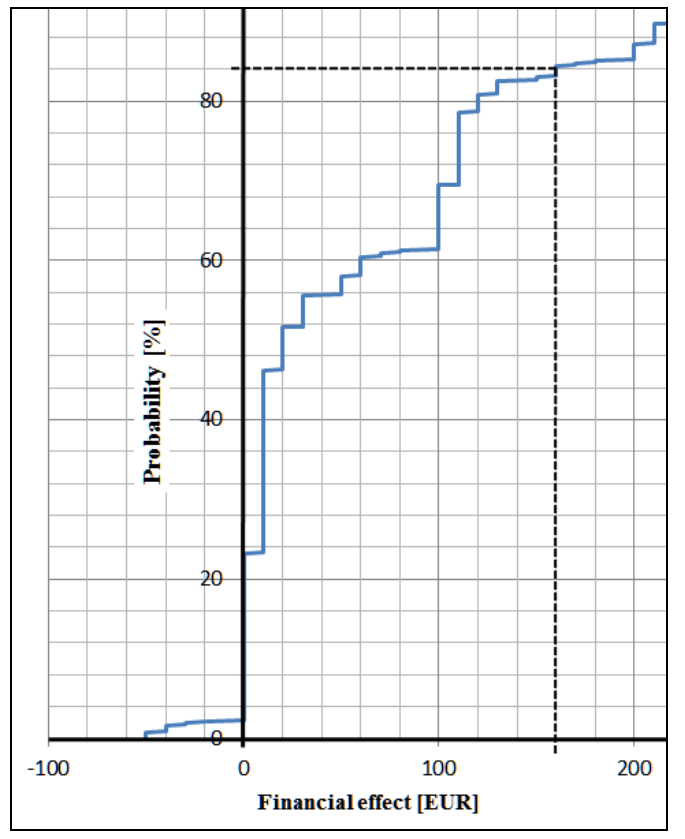

Fig. 1. Probability cumulative distribution function for project risk costs

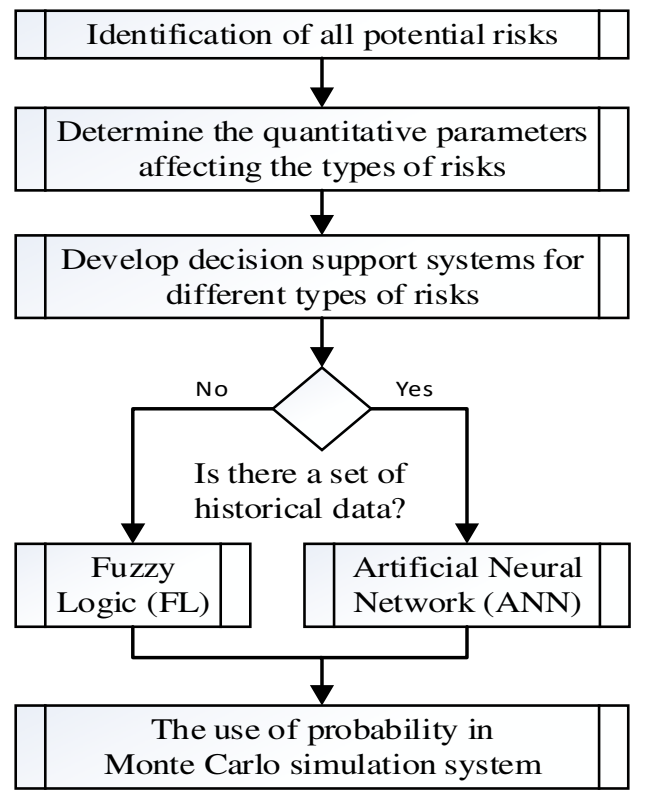

Fig. 2. Algorithm for the development of project risk estimation system for non-standard orders

The first stage of development consists in identification of all potential risks that could affect costs or delivery dates. Next step is to describe the identified risks in quantitative measures. These will provide input data for particular decision-making modules describing the probability of particular risks.

If a system can be fed with tabulated historical data, a decision-making subsystem based on ANN could be created. Otherwise, the application of FL is possible.

SVM was skipped in the present analysis due to extensive computational time, which means it does not meet one of the criterions - time efficiency, and as a result the criterion of applicability.
It ought to be noted that in selection of input vectors for particular modules for determining risk probability it is the historical data accessibility that plays a crucial role. It can be, for instance, assumed that risk R-1 (Subcontractor errors) is influenced by criteria shown in Table 2, corresponding to the intelligent subsystem for project risk estimation shown in the diagram in Fig. 3.

Column 3 Table 2 contains methods for R-1 module input features determination. While to determine feature I-1 is relatively simple, the situation becomes complicated in the case of I-2 and I-5 inputs.

\section{TABLE II. INPUT FEATURES FOR MODULE R-1} (SUBCONTRACTORS ERRORS)

\begin{tabular}{|c|l|c|}
\hline IBS & \multicolumn{1}{|c|}{ Input feature name } & Measure \\
\hline$I$ & \multicolumn{1}{|c|}{2} & 3 \\
\hline I-1 & $\begin{array}{l}\text { The number of tasks within the } \\
\text { manufacturing order that require hiring } \\
\text { subcontractors }\end{array}$ & {$[\mathrm{pcs}]$} \\
I-2 & $\begin{array}{l}\text { The lowest rating of cooperation } \\
\text { history for subcontractor among } \\
\text { external service providers cooperating } \\
\text { in realisation of order }\end{array}$ & {$[\%]$} \\
\hline I-5 & $\begin{array}{l}\text { The lowest score among external audits } \\
\text { in situ at subcontractors }\end{array}$ & {$[1 . .5]$} \\
\hline
\end{tabular}

For instance, determination of a percentage value of feature I-2 requires a prior analysis of timeliness of all subcontractors. This can be calculated from the relationship (2).

$$
M_{1-2}=\left(1-\frac{c}{s_{o}}\right) \times 100 \%
$$

where:

$\mathrm{M}_{1-2}$ - feature value I-2

$c$ - total number of claims from given subcontractor

$S_{o}$ - number of all orders in the past from given

subcontractor

Input I-5 can take the value from 1 to 5 , where 1 denotes low assessment of quality model. Input feature I-5 requires obtaining the results of audits that would cover data from quality assurance systems of each of the subcontractor. Although I-5 feature values are specified by experts, they can be considered as fully reliable. This is because they were obtained in an analysis of appropriate parameters defined as a part of subcontractor's internal quality management system. If this is a certified system, such as ISO 9001, then evaluation based on the parameters is simple. Otherwise, the evaluation requires defining reliable methods of measurement.

Values of individual project risks probability based on the outputs of intelligent subsystems constitute input data for the system of risk cost calculation, based on Monte Carlo simulation.

Fig. 3. Shows the operation of an intelligent subsystem for project risk estimation. On the left side there is an $\mathrm{N}$ element vector of identified input features, which could have an impact on $n$-element set of project risks; hence, $\mathrm{N} \geq \mathrm{n}$. 


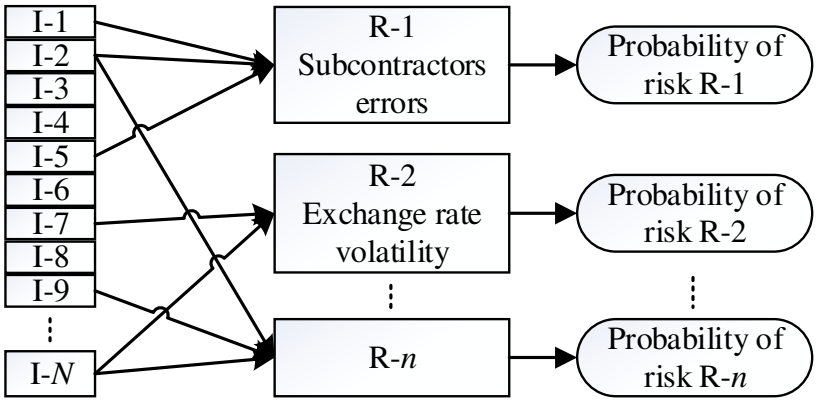

Fig.3. Diagram of an intelligent subsystem for estimation of project risk

Fig. 3 indicates that it is possible for a single output (e.g. I-2) to feed two or more module for R-I risk probability evaluation.

Fig. 4 shows a diagram of a complete hybrid system for the calculation of manufacturing order risk. It can be seen that the system is composed of two major subsystems: Artificial Intelligence (AI) and Monte Carlo Simulation (MCS).

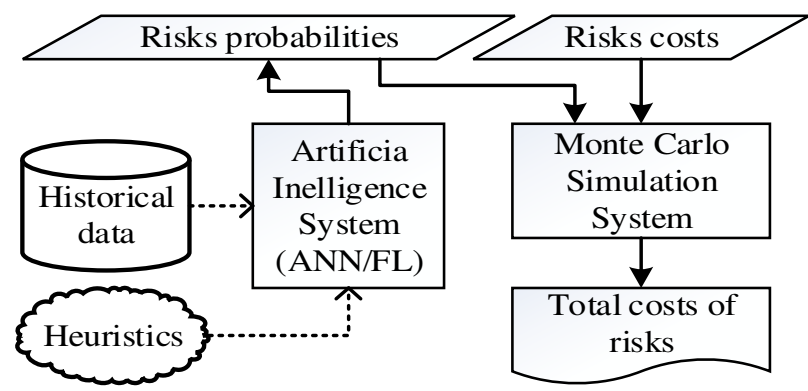

Fig. 4. Diagram of a hybrid system for the calculation of manufacturing order risk

The functioning of AI module is shown in Fig. 3. The process of risk estimation with MCS is shown in Table 1 and Fig. 1. Fig. 4 indicates that the risk probabilities vector, which constitutes the output of AI subsystem, is simultaneously the input of MCS subsystem.

\section{CONCLUSION}

This paper presents solutions for the problem of risk calculation in non-standard manufacturing orders in small and medium-sized enterprises. Highly individual character of particular orders permits treating them as separate projects. The two initially formulated, mutually complementing hypotheses stated that employing hybrid systems based on artificial intelligence produces more accurate results of project risk calculations. The truthfulness of the hypotheses was initially confirmed by introduction of logical and coherent vision of reasoning rules, which could replace the subjective, hence imperfect decisions taken by human.

The algorithm for development of a system of risk estimation for non-standard manufacturing orders was created. We proposed an improved Monte Carlo simulation method with an additional subsystem variant, employing fuzzy logic or neural networks, depending on the availability of historical data.

It should be noted that by substituting cost with time, the presented solution could be easily adapted for risk estimation of order delivery delay in single orders.

\section{REFERENCES}

[1] M. Jasiulewicz-Kaczmarek , "Participatory Ergonomics as a Method of Quality Improvement in Maintenance", B.-T. Karsh (Ed.): Ergonomics and Health Aspects, LNCS 5624, pp. 153-161, 2009.

[2] A. M. Radke, et al. "A risk management-based evaluation of inventory allocations for make-to-order production," CIRP AnnalsManufacturing Technology, pp. 459-462, 2013.

[3] A. Saniuk, et al. "Environmental favourable foundries through maintenance activities", METALURGIJA, Vol. 54 (4), pp. 725-728, 2015.

[4] G. Kłosowski, A. Gola, A. Świć, "Application of Fuzzy Logic Controller for Machine Load Balancing in Discrete Manufacturing System", in: K. Jackowski et al. (Eds): IDEAL 2015, LNCS 9375, pp. 256-264, 2015.

[5] P. Sitek, J. Wikarek, "A hybrid framework for the modelling and optimisation of decision problems in sustainable supply chain management", International Journal of Production Research, Vol. 53, Issue 21, 2015.

[6] A. Rudawska, N. Čuboňova, K. Pomarańska, D. Stanečková, A. Gola, "Technical and Organizational Improvements of Packaging Production Processes", Advances in Science and Technology. Research Journal, Vol. 10, No. 30, pp. 182-192, 2016.

[7] A. Taroun, J. B. Yang, D. Lowe, "Construction risk modelling and assessment: Insights from a literature review", The Built and Human Environment Review, Vol. 32, Issue 1, pp. 101-115, 2011.

[8] C. Rush, R. Roy, "Analysis of cost estimating processes used within a concurrent engineering environment throughout a product life cycle," In: 7th ISPE International Conference on Concurrent Engineering, Lyon, France, July 17th-20th, Pennsylvania USA. pp. 58-67, 2000.

[9] A. O. Elfaki, S. Alatawi, E. Abushandi, "Using Intelligent Techniques in Construction Project Cost Estimation: 10-Year Survey," Advances in Civil Engineering, Vol. 2014, pp. 8, 2014.

[10] N. G. Fragiadakis, V. D. Tsoukalas, V. J. Papazoglou, "An adaptive neuro-fuzzy inference system (ANFIS) model for assessing occupational risk in the shipbuilding industry," Safety Science, Vol. 63, pp. 226-235, 2014.

[11] O. Taylan et al., "Construction projects selection and risk assessment by fuzzy AHP and fuzzy TOPSIS methodologies," Applied Soft Computing, Vol. 17, pp. 105-116, 2014.

[12] I. J. Schwarz, I. P. M. Sánchez, "29 Implementation of artificial intelligence into risk management decision-making processes in construction projects", 2015, pp. 361-362.

[13] E. E. Ameyaw, A. P. C. Chan, "Evaluation and ranking of risk factors in public-private partnership water supply projects in developing countries using fuzzy synthetic evaluation approach," Expert Systems with Applications, Vol. 42(12), pp. 5102-5116, 2015.

[14] A. Idrus, M. F. Nuruddin, M. A. Rohman, "Development of project cost contingency estimation model using risk analysis and fuzzy expert system," Expert Systems with Applications, Vol. 38, Issue 3, pp. 1501-1508, 2011.

[15] J. Hu, E. Shen, Y. Gu, "Evaluation of Lighting Performance Risk Using Surrogate Model and EnergyPlus," Procedia Engineering, Vol. 118, pp. 522-529, 2015.

[16] P. D. Sentia, M. Mukhtar, S.A. Shukor, "Supply chain information risk management model in Make-to-Order (MTO)", Procedia Technology, Vol. 11, pp. 403-410, 2013. 